\title{
The New Enlightenment of Absorptive Capacity Theory
}

\author{
Zenghai $\mathrm{Wu}$, Xiongxiong $\mathrm{Qu}^{*}$ \\ International Business School of Shaanxi Normal University \\ Xi'an China
}

\begin{abstract}
This paper thinks that we can improve the knowledge absorptive capacity of organizations and their employees through training. After theoretical analysis of knowledge absorptive theory and training activities, it is believed that organizations can take the following measures to improve the knowledge absorptive capacity: (1) set up a support network of trainees to encourage them to exchange their learning experience with each other and successfully apply it; (2) improve students' self-efficacy and reduce psychological barriers to learning; (3) support employees in applying the knowledge and skills learned in training at work and allow them to make mistakes in practice by their supervisor; (4) during the training, the problems often encountered by trained employees are used as cases for analysis; (5) choose the technical gatekeepers in the organization as the priority training object.
\end{abstract}

Keywords-Absorptive capacity; Training; Results; Transformation

\section{INTRODUCTION}

In the era of knowledge economy, especially in the present and foreseeable future for a long time, turbulence, impermanence, complexity and fuzziness will become a new normal of the times, called VUCA [1]. Under the normal circumstances of VUCA, maintaining and improving core competitiveness has become a hot topic in organizational management research. In the industrial age, the value of the product mainly depends on the input of material resources. In the 4 era of industry, knowledge is becoming the main input factor of organizing products, such as R \&amp; D, design and so on. The quality and quantity of knowledge and the application of knowledge will become an important core competitiveness of the organization. The quality of knowledge includes the breadth and depth of the industry's knowledge, and the breadth of knowledge helps organize new opportunities for the discovery of the industry and helps to organize the whole knowledge to carry out aggregated innovation. The quantity of knowledge can become the common capital of an organization. The members of the organization can carry out platform innovation based on their own human capital and the common capital of the organization. Unlike knowledge and material resources, it is difficult to buy directly from the market by capital, but as a knowledge-based organization, its knowledge is unique and difficult to be imitated [2]. Therefore, the ability to absorb knowledge

This work was supported by a grant from Shaanxi social fund in 2014(2014D12). becomes a kind of ability that the organization needs to pay special attention to, and the organizational knowledge absorption ability is the function of the individual knowledge absorption ability in the organization. In a sense, training is to improve the knowledge absorptive capacity of employees, especially in theoretical knowledge training.

\section{ABSORPTIVE CAPACITY THEORY}

The theory of absorptive capacity was first proposed by Cohen \& Levinthal [3]. In the paper "absorptive capacity: a new view of learning and innovation", their definition of absorptive capacity is the ability of enterprises to identify new external information, absorb and apply them to the business list, and the ability to create a business. New is crucial. The theory holds that enterprises with the ability to absorb knowledge can not only improve the innovation ability and agility of the organization, but also improve the performance of the enterprises. Cohen\& Levinthal [3] believes that the competitive advantage of enterprises with higher absorptive capacity is more obvious than those with low absorptive capacity.

Zahra and George expand the theory of knowledge absorptive capacity and considers that knowledge absorptive capacity consists of four parts [4]. They are the ability to acquire, digest, transform, retain and utilize. Acquisition mainly refers to the enterprise's previous expenditure, the previous knowledge base, the intensity and speed of the enterprise's acquiring new knowledge and its direction. It needs to be explained that absorbing new knowledge needs to be based on existing knowledge, so the ability to acquire is mainly the knowledge that the enterprise has and the way it can be used to acquire knowledge before it absorbs new external knowledge. Digestibility mainly refers to the existing practices and processes within an enterprise that enable enterprises to Assess, Interpret, Understand and Learning new knowledge. Transformation ability mainly refers to the Add, Delete, Recombine, and Reconfigure for the enterprise to use in the enterprise. The ability to use mainly refers to the ability of an enterprise to change its routines and processes and use new knowledge. Combining Cohen \&amp; Levinthal's definition of absorptive capacity, this paper argues that absorptive capacity should be composed of five parts. In addition to the above four abilities, the ability to judge the value of new external knowledge, mainly refers to the ability 
to judge the value of the new knowledge of the outside world, to judge whether the new knowledge is valuable to the company or organization or not. Bring value added or benefit to the company. At present, most of the research on absorptive capacity is about the absorptive capacity of enterprises, and less attention is paid to individual absorptive capacity. This article focuses on individual absorptive capacity, and the main content is how to improve individual absorptive capacity.

\section{TRAINING MANAGEMENT}

According to the training process, training management consists of four parts. They are demand analysis, training plan, training implementation and training effect evaluation. Demand analysis is the basis of training work by analyzing the current performance information of organization and employees, comparing target performance, analyzing performance gap, and finding out the problems that can be solved through training. In the specific demand analysis, the three-level analytic method is generally adopted, and [5] is first analyzed from the three aspects of organization, task and personnel. The training plan is a record in a logical sequence. It is a pre-system setting of learning content, time, field, lecturer, trainee, training mode and training cost based on the strategy of organization, based on the strategy of organization. Training implementation is the implementation of a well-done training program. The main contents are: making and printing training materials; inspecting training teachers' qualifications and hiring trainers suitable for the organization; visiting and inspecting training sites, arranging training sites ahead of time; preparing appropriate teaching equipment, such as microphone, loudspeaker, projector, electricity. Brain, pens and whiteboards, and so on; consult with the leaders of the trainee department, determine the training time, arrange the personnel of the Department to take part in the training; the training organizers need to supervise the execution of the training program all the way, and begin to evaluate the training project before the training, one until the end of the training. The evaluation of training effect refers to the evaluation of the whole process from the beginning of the training project to the training content, the advantages and disadvantages of the training, the timely recording of relevant information, and the improvement in the next training project. If digital measurement can be carried out, it is best to carry out the digital evaluation and even to analyze the income of the investment.

\section{BY TRAINING, IT IMPROVES THE ABILITY OF ORGANIZING KNOWLEDGE TO ABSORB KNOWLEDGE.}

Training is an effective means of management. The manager uses the way of training to convey his intention, compared with the following two advantages: the meeting, the report, the document and so on. One is that in the training, the manager and the subordinates are the relationship between teachers and students, the psychological relationship is more harmonious and easier to communicate and communicate, the effect of communication and acceptance is better and the subordinates are carried out. The consciousness of guiding intention is higher; two is that during preparing lessons and teaching, the manager can organize their thoughts more systematically, and in the communication with the students, they can also make these ideas more perfect, thus making the decision more scientific.

Training is the main way of human resource development. For enterprises, training is the input to the development of the core resources of human resources. Compared with other inputs, this kind of investment can bring more rewards to enterprises, and its benefits are huge and comprehensive and long-term. Training is the development of potential abilities of employees, not only the supplement of knowledge, but also the training of skills. Its purpose is to promote the full and full development of employees, thus bringing endless vitality to enterprises.

Training is a magic trick to keep the passion of work. People who take part in training actively have rich insights in the process of accepting new knowledge and new information. The combination of these insights and experience in work is very easy to generate sparks of creative thinking and give people spiritual encouragement. Often "charging" can enable people to maintain strong work enthusiasm. At the same time, employees who focus on personal development tend to regard training as the highest reward for enterprises. Especially when training is combined with the career design of employees, it can inspire employees' enterprising enthusiasm. It is not difficult to foresee that an enterprise that provides less training for employees will be unattractive, and the firm morale that pays attention to the development of employees through training is inevitable.

Training is the necessary way to improve the management level. With the increasingly complex and complex external environment of the enterprise today, the development ability of the enterprise depends more on the quality of the managers. Therefore, the learning and training of the managers is of great significance. Obviously, the higher the level of management, the more important and urgent it is to learn and train. Only the senior managers have rich knowledge, open vision, foresight and innovative thinking, can the correct decisions and ideas be formed, thus promoting the smooth expansion of the work of all departments. Strategic errors are more serious than tactical errors, and tactical errors are more serious than technical errors Therefore, the decision level training is prior to the general management training, and the general management training is prior to the general staff training. The head of the state listened to the experts' lectures, and the big enterprises trained the 
senior managers at high cost, all of which reflected the deep understanding of the management training.

Training is a matter of great importance. It is closely related to the development of the enterprise. We should never ignore it. We should start from the most basic work of training. We should set out from the analysis of training needs, make out an efficient training plan, carry out the training plan carefully, carry out the training plan, and evaluate the effect, to ensure the real achievement and effect of the training.

\section{A. In the phase of analyzing training demand}

When conducting training demand investigation, focus on the demand for employees, especially the gatekeeper. What is the gatekeeper? The person who is a core member of the organization, the key to organizing the core technology. In terms of learning from external knowledge, especially in the organization of new technology knowledge, mainly dependent on the organization of the gatekeeper. When absorbing new knowledge, employees need to make a basis for relevant knowledge to make new knowledge. The knowledge staff are mainly focusing on the gatekeeper. Secondly, participating in training are also a human capital investment, with the training of the "gatekeeper," to improve their human capital stock, and enhance the competitiveness of the labor force market. To improve the value of training staff involved in the training of the new knowledge and motivate the staff of new knowledge. Hence, when it is determined to make training for participants, the "gatekeeper" is preferred.

\section{B. The phase of training plan and the implementation}

It is focused on the ability of students to absorb the ability of absorptive and transformation, as well as knowledge of new knowledge can greatly influence the learning process. With new knowledge, the staff can interpret and digest new knowledge with their own knowledge, and hence, during the choice of training teachers. We should choose some teachers which are able to make new knowledge with employees. In this way, the pressure of students will also be reduced and easier to accept. To improve the ability of students to transform new knowledge, they can be used in training and training methods. In terms of students and students, they work in students for a period, in the practice of students, as well as consultants to guide students to acquire new knowledge of knowledge. Case teaching is mainly the case of teachers, to teach new knowledge, and put new knowledge into the context of new students and help guide students to absorb new knowledge. To improve the integration of new knowledge, students also include lectures and talks, as well as students learning new knowledge, according to their own understanding of new knowledge. As we learn from other students, and express their understanding and opinion, as well as comments in the training division, as well as comments on the participants. With the error of understanding, we can also improve students' understanding of new knowledge, and communicate with new knowledge. With the continuous communication of new knowledge, students can make a consensus on new knowledge. In future work, students can cooperate about new knowledge.

\section{The phase of valuing the training work}

During the training process, the entire training process is completed in formal training. It is also a machine learning effect, which is the use for new knowledge. Factors affecting the transformation of students training can be divided into external factors and internal factors. The external factors mainly refer to leadership support, colleague support, and technology or device support. Application techniques of self-efficacy and new knowledge.

Leadership supports direct leaders to the training project, and whether to support employees in real work, the higher the support for direct leadership. The more helpful the staff will be transformed into practical work [7]. The leaders can provide employees with the opportunity to practice new knowledge. Students will have a better opportunity of maintaining learning, compared with employees who have no practice opportunities, with the opportunity to practice, to maintain their ability [8]. Colleagues support is built by training staff to communicate with each other face to face, to communicate with each other face to face, and communicate with each other face to face. They can share their successful application in their work, while learning new technologies and devices are able to do it in time. During the continuous process, students can improve the use for new knowledge.

Students motivated mainly by learning knowledge, mainly from external income, internal earnings, and external earnings, including money, promotion, etc. The internal income includes the increase of human capital, can hire sexual capital, can obtain new knowledge, the pleasure mood that gets new knowledge. In the process of early training demand analysis and training plan. We need to think about the motivation of the students. The self-efficiency is the confidence of the individual to achieve our expectations. In the training work, the driving force of training staff learning and progress are high and confident they can completely master the training contents. Because of the low efficiency of self-efficiency, it prevents employees from learning [7]. Improve the training of self-efficiency. It can be used by several consecutive successful practices and advances to help students improve their self-efficiency. During the practice, students are using the machine learning process. Like each student participates in training and learning is the same knowledge, but in practice, each student may have a different context. These different situations may be a different manifestation of the same reasons. Hence, we need to see the essence, the key and core of the problems. To solve the problem of solving problems, we need to have certain solutions. This area has improved and can be solved by sharing successful experiences. 


\section{CONCLUSION}

Therefore, to improve the organization and staff knowledge absorption capacity. You can start with the following:

(1) Establish a network of support among the trainees. Support network helps employees to communicate with each other on learning knowledge and share successful learning experiences. Furthermore, some positive events can be used to motivate employees ' knowledge sharing motivation and reduce transaction costs within the organization.

(2) Improve students' self-efficacy. Low self-efficacy is not conducive to staff learning new knowledge and skills, before attending the training, can carry out the training of self-efficacy, reduce the psychological barriers to learning trainees.

(3) The employee's direct leadership supports employees in applying the knowledge and skills they have learned in their work, and tolerates the mistakes made by employees in applying new knowledge and skills. The influence of leadership support on the transformation of training effect is most obvious, the leader grasps the most resources which the staff needs to work, when the leadership trusts the staff, supports the staff, the staff has the more opportunity to practice the knowledge and the skill, is more likely to practice the success.

(4) Before training, the trainer communicates with the training assistant of the organization of the Training object, collects some cases of the organization, and uses the student's case as the analysis object in the training process. Understand new knowledge, need to have corresponding basic knowledge as support, and use the case in the organization, the staff's acceptance degree is higher, the degree of familiarity is also high, the study psychology cost is low, can learn new knowledge without needing to supplement basic knowledge.

(5) The core object of training is the technical gatekeeper of the Organization. They are part of the organization's core competencies, maintaining and improving the technical and intellectual reserves of these people, helping to improve the uniqueness and difficulty of the Organization's core competencies, and helping to create more value for the company.

\section{REFERENCE}

[1] Liu Xiaoxi, Zhang Hong, the challenge of human capital investment in the era of human capital [J], Tsinghua management review, 2015 (10): 50-54. (In Chinese)

[2] Yan Haifeng, Cheng Peng, who was able to absorb comments [J]. Management review, 2009,21 (8): 95-103. (In Chinese)

[3] Cohen W M, Levinthal D A. Absorptive capacity: A new perspective on learning and innovation [J]. Administrative science quarterly, 1990: 128-152.

[4] Miles J A. Management and organization theory: A Jossey-Bass reader[M]. John Wiley \& Sons, 2012.

[5] Xu Fang. Training and development theory and technology [M]. Fudan university press, 2005. (In Chinese).

[6] Niklas Luhmann. Trust: a simplified mechanism of social complexity [M]. Shanghai people's publishing house, 2005. (In Chinese)

[7] Wang Xin. The transformation of factors affecting factors of training and training [J]. The Chinese market, 2011: 116-117. (In Chinese)

[8] Xu Fang trained in the transformation of training work environment [J]. Human resource development in China: 45-4650. (In Chinese) 